\title{
Solving Tourism Management Challenges by Means of Mobile Augmented Reality Applications
}

\author{
Ahmad Ghandour, Al Ain University, UAE* \\ Aliya Kintonova, L.N. Gumilyov Eurasian National University, Kazakhstan \\ Natalya Demidchik, L.N. Gumilyov Eurasian National University, Kazakhstan \\ Elena Sverdlikova, Lomonosov Moscow State University, Russia
}

\begin{abstract}
The purpose of the present article was to examine the use of mobile augmented reality technologies in the process of planning and organizing tourist activities. The analysis of the attitude of TUI Showroom's clients and managers of Russian travel agencies to the application of immersive technologies in travel consulting unveiled several possibilities for the practical use of mobile augmented reality applications in the travel business. The study concludes with the opinion that stimulation of the client's interest in the historical and cultural context of the tour by providing additional argumentation and high-quality information on the marketing proposal in a new, unusual manner forms the cultural, epistemic, and educational values of augmented reality, necessary in sales, personnel training, and interaction with business partners.
\end{abstract}

\section{KEYWORDS}

Immersive Technologies in Tourism, Interactive Sales Offices, Mobile Augmented Reality Applications, Tour Operator and Travel Agency Activities

\section{INTRODUCTION}

The current exponential growth of a technology-based service environment has increased consumer demand for self-service, as well as the industry-wide goal of reducing costs through automation. It has become a catalyst for the infusion of technology in today's service economy (Rivera et al., 2015).

In the present day, information and communication technologies are transforming the travel industry all around the world. Travel experience is now closely linked with digitalization (tom Dieck $\&$ Jung, 2018). The journey today starts with the internet, which offers a broad range of possibilities and makes other people's feedback the main criterion for making a decision (Rezaei et al., 2016). The digital reorganization of the tourism sector has gradually led to the formation of a new business paradigm, which is now rapidly changing the tourism industry structure and therefore opens up numerous opportunities and prospects for travel companies, being a key factor in their competitiveness (Qiao et al., 2019). One of the technological developments of today is augmented reality (AR) with a constantly expanding application field (Özkul \& Kumlu, 2019). 
The potential of mobile devices is growing at an impressive rate, changing the way tourists collect and access information (Shang et al., 2017). Mobile applications enable people to access a variety of services and resources without using a web browser (Tan et al., 2017). Cameras, Global Positioning System (GPS) sensors and internet connection open the way toward a new manner of perceiving tourist destinations through contextual information. With context-awareness services, tourists gain access to a new interactive experience. All these features are included in the applications supplemented with AR engine based on geolocation services (Pierdicca et al., 2019). While observing the world in AR, tourists also see virtual objects overlaid on reality. Usually, this is achieved by interacting with one's own smartphones or digital cameras, by using see-through displays, or more recent techniques such as spatial augmented reality (SAR) that can be used on large surfaces as spatial-aligned wall projections (also commonly referred to as 3D video mapping) (Loureiro et al., 2020).

\section{LITERATURE REVIEW}

High diversification, mobility and ease of use of digital technologies open up extensive prospects for their application while organizing tourist activities (Dirin \& Laine, 2018). The tourist can customize the search for information in the mobile application according to personal preferences, age, knowledge and profession, comparing reality with various multimedia formats offered by the AR (video, sounds, 3D images) (Tussyadiah et al., 2018). Virtual reality (VR) technologies are able to separate people from the real environment and provide them with both visual and audio stimuli, thereby allowing them to feel in a completely different world (the effect of telepresence) (Ali, 2016). Many AR applications are integrated with the most commonly used social networks, giving the possibility of updating one's social status in real time, to use tags, to share photos and opinions and to exchange recommendations with other tourists (Yung \& Khoo-Lattimore, 2019). Such an activity builds a stronger sense of confidence and awareness in a traveler, allowing him/her to gain a more vivid experience by interacting with other users posting virtual content (Kounavis et al., 2012). The modern market is actively promoting the development of such forms of interaction between the tourism industry actors as virtual communities (Yin et al., 2021). Hence, the entire pre-purchase process is integrated into online systems that allow tourists to connect to a community where at least the part of the whole travel experience happens virtually. A potential tourist can use VR to have a first short immersive experience of several destinations or locations (e.g., attractions, hotels, museums, restaurants) before deciding which destination, hotel or tour to choose. During the real visit to the destination, tourists can keep in touch with other members of virtual communities, who may suggest some attractions, tours, or places nearby that are worth visiting - all in real-time through the use of mobile phones and AR (Loureiro et al., 2020).

VR is considered a promising technology for the tourism sector due to its innovative possibilities of displaying tourist attractions in 3D mode and generating a complete virtual environment where a user feels just as immersed as in everyday life (Nayyar et al., 2018). AR is a real-time imaging technology capable of introducing more information into the real world by overlaying visual, auditory, tactile, or even olfactory data on physical objects (Barðeld et al., 2013). AR technology is widely used in various sectors of the economy where there is a need to expand the information perception or provide quick access to instructions during production processes. As a variation of VR, AR allows integrating real and virtual environments to provide additional information about something through digital content. Furthermore, needless to say that it is often used in conjunction with VR and MR (mixed reality) technologies (Nayyar et al., 2018).

The use of advanced technologies in the tourism industry has an essential role in attracting tourists and creating competition among destinations and businesses (Özkul \& Kumlu, 2019). VR and AR environments can be used to significantly promote tourist destinations (Guttentag, 2010). Travelers can download specialized applications to their mobile devices to access a wealth of information about places, restaurants, hotels, cultural attractions, tours, and more (Nóbrega et al., 2017). VR and AR 
technologies have the potential to revolutionize the travel experience by making possible the planning, previewing and accessing location-based information in an interactive and simple manner from various places. Through mobile applications, users can preview and book a hotel, access tourism-related data, navigate around their destination, translate written and spoken signs or conversations, find restaurants and entertainment venues (Nayyar et al., 2018).

VR and AR are deemed particularly suitable for supporting the commercial decision-making process regarding intangible products such as organizing parties, events, or tourist trips (Nayyar et al., 2018). A significant number of international travel companies have invested in VR and AR applications to help potential clients make purchasing decisions. Immersive virtual environments, powered by new and emerging technologies, change the way travel agents incentivize their customers (Lemon \& Verhoef, 2016).

The widespread adoption of digital technologies in the hospitality and tourism industry increases interest in using technological solutions in travel agencies' activities. These solutions are expected to maximize profits, ensure competitive advantages of a company from a strategic perspective and ease the process of addressing tourism management issues. VR and AR technologies bring new opportunities for tourism in planning, management, development, education and creation or transformation of tourism experiences. In this regard, this research aimed to study the use of mobile AR technologies in the process of planning and organizing tourist activities. In order to achieve this goal, the following tasks were set:

- Review available mobile AR applications in the hospitality and tourism sector;

- Identify the areas in the tourism field where VR and AR technologies can be applied;

- Investigate the experience of TUI international tour operator in the application of VR and AR technologies in pre-purchase practice based on the infrastructure capabilities of TUI Showroom interactive offices in Russia and Ukraine;

- Study how an innovative commercial proposal affects a customer's decision to book a tour;

- Reveal business opportunities of mobile AR applications in the tourism industry;

- Highlight the key benefits from introducing innovative technological tools in the modernization of management, production, and marketing functions of travel agents.

The purpose of this article was to study the use of mobile AR technologies in the process of planning and organizing tourist activities.

\section{MATERIALS AND METHODS}

\section{Mobile Augmented Reality Applications for Guiding Tourist Activities}

The first notable steps in the introduction of mobile AR applications date back to 2009. Novel then, these technologies allowed digital enhancements to be layered over an existing reality or real-life scenario. A good example of a mobile application designed specifically for the tourism industry to enhance the visitor experience is Tuscany, an interactive real-time travel guide. Another world-famous example is the AR-based game Pokémon GO. It makes use of "PokéStops", strategically placed at sightseeing locations, such as monuments and other public areas of interest. In the game, these locations are displayed with a photo and a brief description. Players can expand their knowledge by collecting PokéStops of historical, artistic, or cultural value in real life, while travel agencies can design new tours following the location of these PokéStops (Nayyar et al., 2018).

Being the most world-changing technologies of the 21 st century, VR and AR offer many useful applications to solve the urgent challenges of tourism management. These applications are attracting the increasing attention of both tourism professionals and researchers. Immersion technologies are 
actively introduced in companies responsible for organizing various tours as well as those providing transport, accommodation, meals, excursion services and entertainment.

In modern tourist practice, mobile AR applications supplemented with navigation and route planning functions continue to be excellent guides for tourists in unfamiliar places. Such applications are among the most important tools for gaining travel experience since they help one find the right address and map a route to the desired destination. Popular examples of such services are Google Maps, Google Street View, Google Earth, Apple Maps, Yandex Maps, Bing Maps, MapQuest, SAS. Planet, and Yahoo! Maps. Another famous AR application is Wikitude (n.d.). It allows one to find historical and cultural sites, architectural attractions, metro stations, common meeting points and can even scan the faces of passers-by and find them in social networks. Yelp Monocle views a map of shops, markets, hairdressers, gas stations, pharmacies and hospitals around. Travel With AR - AR Portal application enables one to take a virtual tour of the desired destination just by logging into the virtual portal.

AR is widely used when conducting excursions, studying historical and cultural objects and thus it remains a widespread museum practice. The traditional excursion guides are increasingly frequently being replaced by the possibilities of AR. Now, it is enough to direct the gadget to the point of interest to get additional information. Interactive digital guides are widely used in museums to breathe life into exhibitions and turn an ordinary visit into a dynamic, exciting performance. One of the brightest and most significant examples in this field is the Russian multimedia guide Artefact. It contains data from 157 museums, among which are the wide-known State Russian Museum, the Tretyakov Gallery, and the Pushkin State Museum of Fine Arts. The principle of this mobile application's operation is quite simple: a user points the camera of any mobile device at the work of art and receives full-fledged information on an object, including its fragments, sketches, the view before restoration, and an audio tour (Artefact, n.d.). A similar program is the Digital Binocular Station (n.d.), designed to enhance the experience of historical places, museums, landscapes, and exhibits via specially developed usable digital content.

Locals.Maps.me (n.d.) mobile application allows one to discover cities with locals and connoisseurs of historical and cultural heritage as it helps travelers and locals to find each other. In fact, it is a community of local guides from all over the world where they can conduct tours for free or at a fixed hourly rate. Over 500 registered guides from different parts of the world, including Russia, have already joined the project.

One more increasingly popular practice in today's tourism industry is the technology of virtual tours. It provides potential customers with the opportunity to see certain tourist destinations, resorts, hotel facilities, museums, restaurants and local attractions in a multimedia format. The main advantage of AR and VR technologies in the tour marketing support lies precisely in the effect of presence, which can create a strong emotional link between a place and a client. Travel companies use AR for a better presentation of tour services and content since they offer the most realistic view of future leisure time by immersing a client in a virtual environment. Besides, this technology allows choosing the optimal vacation program based on personal emotions and feelings. The immersive way of presenting information enables one to more realistically evaluate the marketing proposal and plan a tour as efficiently as possible. Coral Travel tour operator offers its clients a mobile application that significantly simplifies vacation planning and makes the holiday brighter and more eventful. By adding the details of a tour booked in Coral Travel, a traveler is provided with all the necessary documents, contacts, as well as information on visa status, transfers, excursions, and all changes concerning any aspect of a tour in online mode. The official Coral Travel (n.d.) mobile application is supported in 3 languages: Ukrainian, Russian, and English. In a similar vein, under the umbrella of TUI tourism company, the TUI Destination Experiences is carrying out tests of next-generation AR travel experiences in Palma de Mallorca. Together with Mixed Reality I/O, TUI Destination Experiences has launched a trial for the use of AR during excursions and activities, testing the technology via glasses that display information, images, video and 3D models. AR allows holidaymakers a new, more exciting access 
to historical facts and stories and takes into account the increasing desire of guests to explore cities and towns on their own (Tui Group, n.d.).

Prominent examples of the use of AR in the hospitality and tourism industry are applications developed for Marriott Caribbean \& Latin America Resorts, Holiday Inn, and Best Western Hotels \& Resorts. Marriott Caribbean \& Latin America Resorts has launched a new iOS application that uses AR to give tourists an expanded view of many dynamic destinations in the Caribbean and Latin America. This application enables vacationers to "enter" a resort and uncover the colorful and immersive experiences of every desired place, thereby improving vacation planning and inspiring customers to book a trip. The application users are offered a list of available resorts to choose from, as well as six different scenes for each resort to explore, including pools, restaurants, beaches, rooms and spas. This application puts tourism agencies' clients directly into the hotel in such a realistic way that they can almost feel the ocean breeze and hear the waves outside the windows (Taylor, 2018). The activity of the Holiday Inn is also a good example of how hotels can use AR to create new experiences for their guests. The first AR application for a hotel setting was launched by the Holiday Inn in 2012, for the London Olympic and Paralympic Games. In such a manner, it has offered its guests the opportunity to see Olympic and Paralympic athletes through AR technologies applied in the hotel's rooms, lobby, and reception (Minazzi, 2015). One more successfully used AR application is BWVRE, designed to promote Best Western Hotels \& Resorts. Through BWVRE, tourists can experience the hotel's public areas, experience interactive tours of the hotel's pool, lobby, fitness center and rooms by means of 360-degree 3D video, captivating narration, and smooth music. Before booking, visitors can explore more than 2,200 Best Western properties in North America on all HTML5-supported platforms, including Google Maps, Google Search, YouTube, and Facebook (Best Western Hotels \& Resorts, 2018).

The AR market has been steadily developing as the technology matures and is expected to reach $\$ 4$ trillion and grab almost $28 \%$ of mobile commerce market share by 2030 (Van Krevelen \& Poelman, 2010).

\section{Research Design}

The development of attractive and competitive travel products that can satisfy the needs of a modern tourist is the main goal of such international tour operators as TUI, Coral Travel, Join UP, TEZ Tour, Pegas Touristic, Anex Tour. Since the tourist product is based on partnerships of tour operators with transport companies, hotel complexes and resorts, animation and excursion organizations, and local tour operators, the final proposals may lose their uniqueness for a client. Due to the wide range of similar offers, tour choice is often motivated by the best price. This tendency is especially relevant for mass tourism destinations in Egypt, Turkey, and United Arab Emirates; however, it is this mass tourism that provides the main commercial success of tour operators.

In the modern realities of running a tourism business, travel companies are faced with nextgeneration competition. Here, the main share of the overall possible profit belongs to those keeping up with innovative technological progress and actively introducing immersive technologies into production and marketing processes. The world-famous brand, innovative approaches to tourist services, high tourist product quality, and numerous new destinations are the areas of management decisions, the effectiveness of which can provide a company with dominant advantages in the tourism market.

The present article studied the experience of using VR and AR technologies in the travel industry on the example of TUI international tour operator's interactive offices located in Russia and Ukraine. Apart from that, the paper also examined the attitudes of clients to these innovative marketing solutions. The experimental work was carried out in five interactive TUI Showroom offices located in the Aviapark shopping center (Moscow), Metropolis shopping center (Moscow), Nikolskaya Plaza business center (Moscow), Gulliver shopping center (Kyiv), and Dream Town 2 shopping center (Kyiv). 
Along with the advice on choosing a tour, interactive office visitors were proposed to test the unique technology of immersion in the dream site using the following innovative devices (Tui Group, n.d.):

1. Smart chair that reads emotions. While sitting in this chair, a client is provided with a two-minute video. Based on his/her emotions and facial expressions, the chair will recommend the ideal country, resort, or vacation type.

2. Head-mounted display. Visitors can dive into the land of their dreams right in the TUI Showroom. Underwater worlds, hotels, the best beaches in a 360-degree format. Modern technology allows one to imagine a future vacation in advance.

3. Interactive touch panel with 3D tours. A client can have a virtual walk around the world's best hotels before arriving there.

4. Land of Legends photo zone. This thematic photo zone provides the possibility to take a vivid photo as a souvenir and print it out right in the TUI Showroom.

The dynamic interaction of technology and a client, as well as the increasing convenience, depth of visit and virtual perception, is achieved by such technological elements of AR-based mobile application, as stereoscopic imagery, interpupillary distance (IPD), field of view (FOV), head-mounted display (HMD) resolution, and on-board processing and operating system (Figure 1).

The study involved 80 TUI Showroom's clients planning to travel during the 2019 tourist season. The expert group was made up of managers of travel agencies (34 people) operating in the Russian market (Figure 2).

\section{Research Limitations}

This study made it possible to identify the advantages of introducing mobile AR applications into travel companies' pre-purchase practices. However, it is worth noting that the range of applications of immersive technologies in tackling tourism management challenges is quite extensive, from planning and developing tours to the formation of a tourism experience in a new innovative format.

\section{RESULTS}

Mobile AR applications assist in ensuring high-quality management of a travel agency network and allow tour operators to plan and manage tourism activities effectively. The organization of interactive marketing programs and tours' presentation by means of AR technologies can provide additional value for travel products and give potential tourists the opportunity to gain a virtual experience of travel activities before booking. Interactive information resources and educational programs make it possible for travel agencies to modernize partnerships, prioritize tour operator's products, and deliver high-quality marketing support when selling them. The availability of a reliable navigation system and interactive information support contributes to a sense of confidence and security while gaining a travel experience. For a tour operator, this is an opportunity to consolidate and maintain the image of a reliable and high-quality travel arranger.

The investigation of an innovative way of presenting a commercial proposal using AR and its impact on a client's decision to book a tour indicated a high level of this technology efficiency. The results showed that $95 \%$ of customers who used TUI Showroom services booked a tour (see Figure 3). For the majority of respondents (87\%), the opportunity to immerse themselves in a virtual experience helped objectively evaluate a commercial offer and make a more rational and optimal decision. Besides, among all the surveyed, 93\% appreciated the quality of given information; $76 \%$ enjoyed the high level 
Figure 1. Technological elements of AR-based mobile application
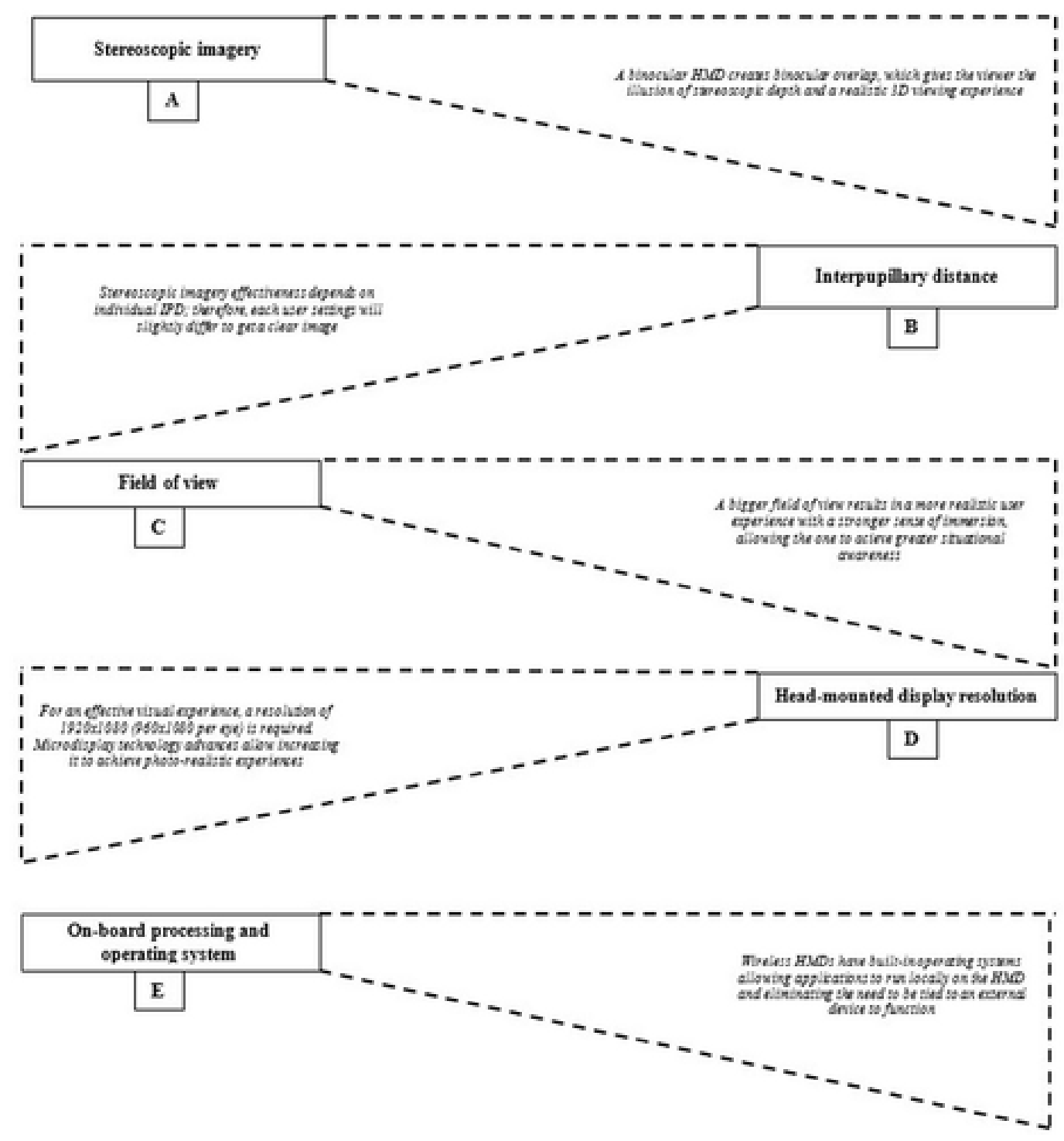

Source: developed by the authors based on (Nayyar et al., 2018).

of innovation, professionalism and services offered in the travel planning process; $85 \%$ indicated a desire to use TUI Showroom's assistance once again. The managers of Russian travel agencies were highly interested in TUI's innovations and confirmed their usefulness and effectiveness in consulting a client at the stage of booking.

From the perspective of the practical use of mobile AR applications in travel companies' activities, the respondents identified several key benefits from immersive technologies' introduction in management, production, and marketing functions (Figure 4). 


\section{Figure 2. Study participants}

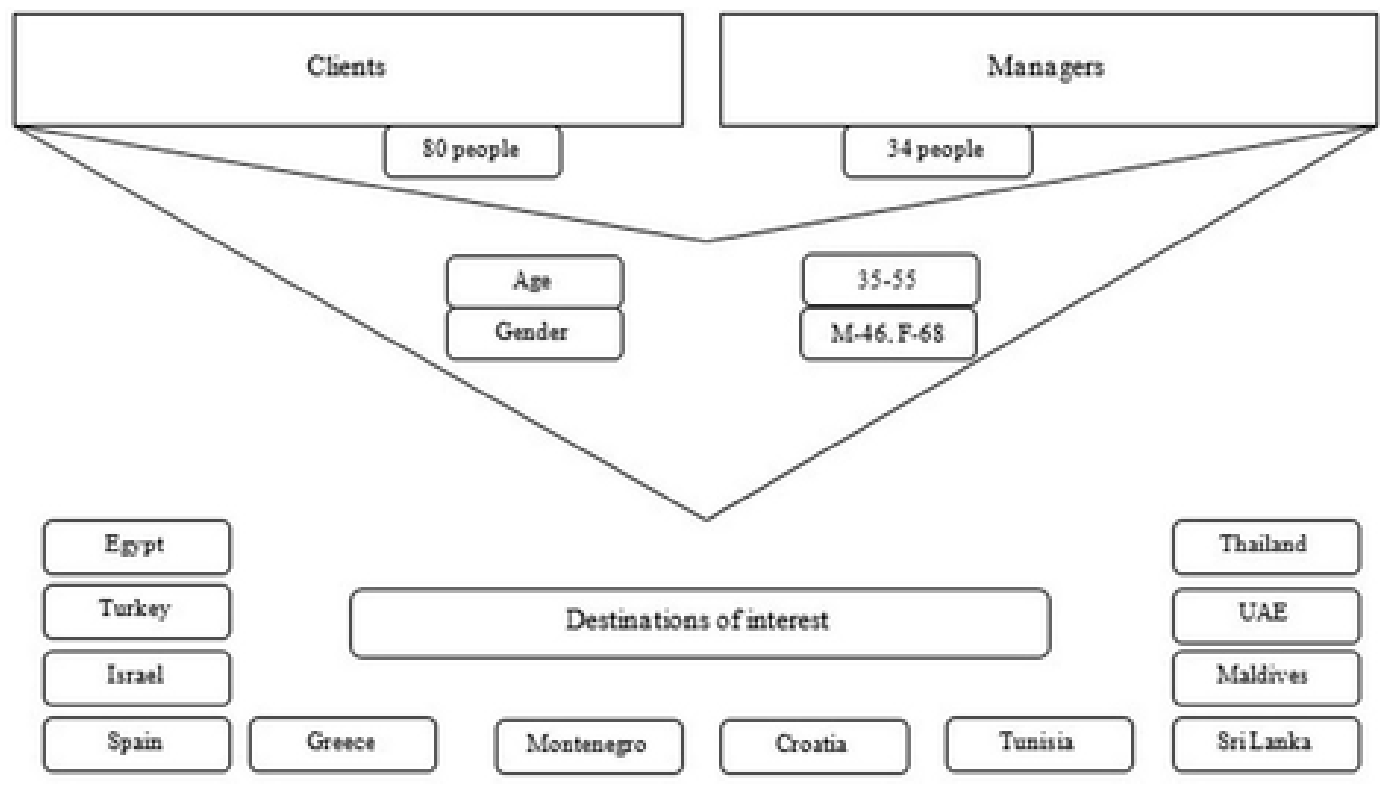

Source: developed by the authors.

Figure 3. Respondents' evaluation of TUI Showroom services

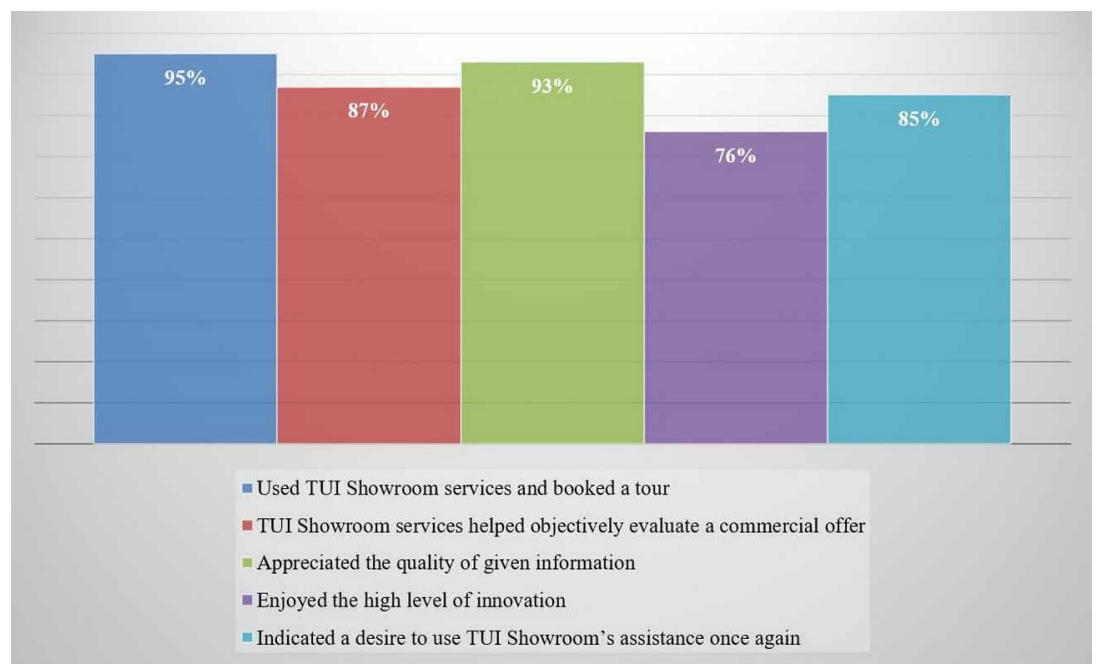

Source: developed by the authors. 


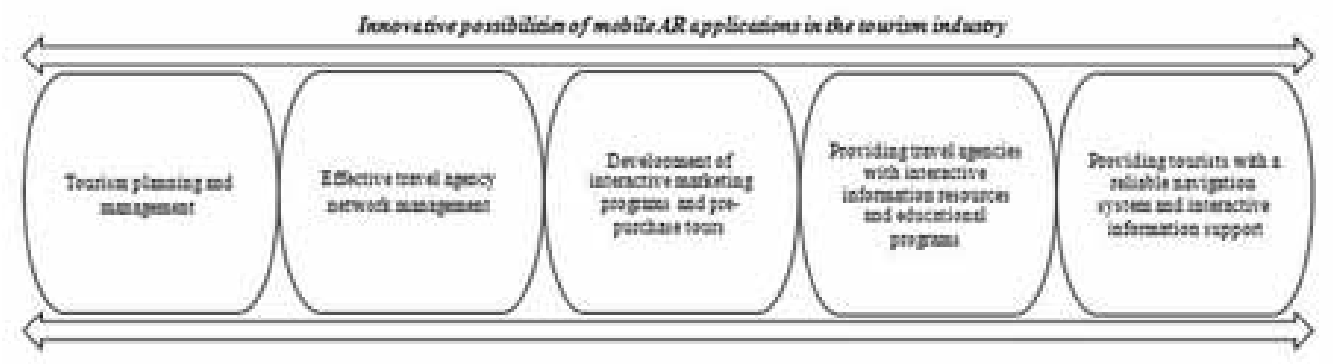

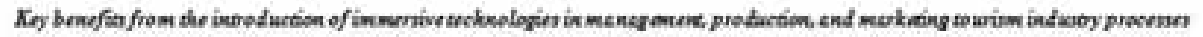

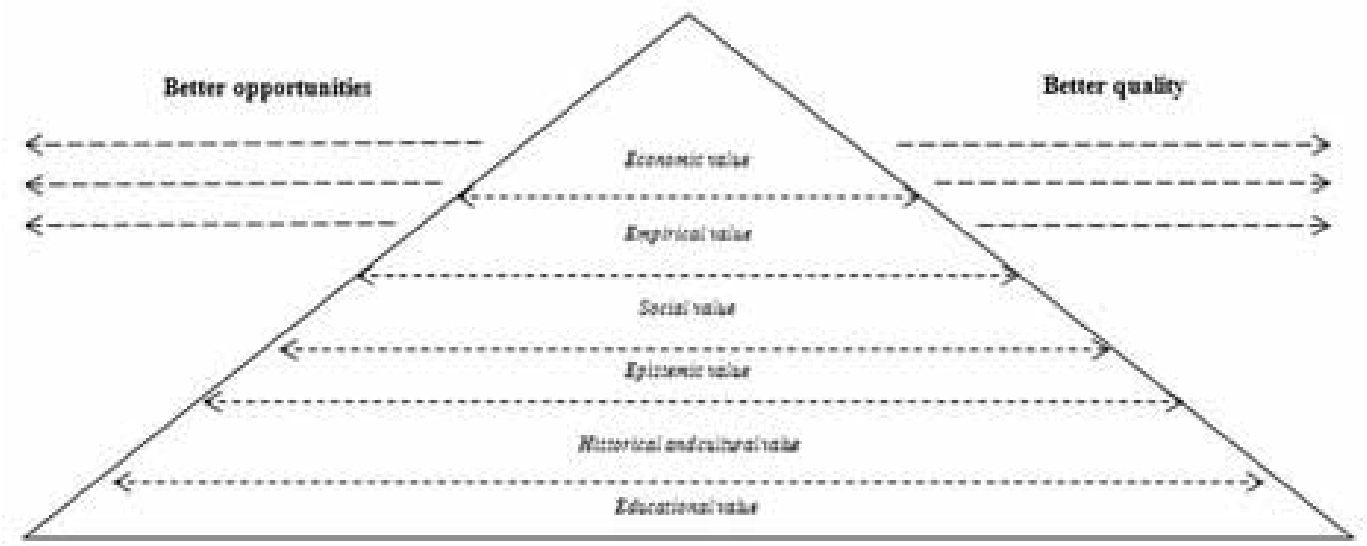

Source: developed by the authors.

\section{Suggestion}

The economic benefit from the adoption of AR lies in attracting new target markets and expanding sales due to the increased customers' interest in innovative offerings. In addition, personal interactive participation in tour selection can influence the final decision to purchase it. Emotional and cognitive experiences in the process of innovative consulting with AR technologies can evoke the urgent client's desire to gain a new tourist experience. In this regard, the introduction of AR technologies into a travel agency's activities is an excellent marketing tool for attracting customers and expanding the sales network. The empirical value of AR-based technological solutions lies in enhancing customers' emotional attachment, trust, and loyalty by opening up new possibilities for perceiving the marketing proposal and providing enhanced information support. The social value of the AR applications in the travel market stems from the creation of a competitive and successful brand of a tourism provider through a travel company's presence in the virtual online space and provision of high-quality tour information. The presentation of travel experiences, availability of customer communication, feedback, and suggestions create a favorable environment capable of attracting new clients. The epistemic value of AR arises from shaping new interactions with customers and capturing their attention based on an increased interest in new technologies and a desire to experience something new. The historical and cultural value of AR lies in raising consumers' interest in the history, culture, and traditions of the desired destination by presenting information in an unusual manner with additional reasoning and details. The educational value of AR lies in the generation of high-quality information support 
concerning every aspect of the tour, which is necessary for sales, personnel training, and interaction with business partners.

\section{DISCUSSION}

VR and AR are actively used in tourism marketing. Recently, there has been a growing awareness of the importance of emotions in shaping tourist experiences and making them memorable (Han et al., 2019). The intangible nature of travel experience poses a challenge for both providers (the need to convince travelers to choose a certain destination) and consumers (deciding where to spend their vacation). Imagination is especially critical in planning one's dream holiday. For this particular reason, the idea of an online travel store considerably improves the planning and booking experience for customers. A good confirmation of this is, for example, the interactive design of the ADDIN travel agency created by FAL Design Estrategico (Sao Paulo, Brazil), which immerses a visitor in a visualsensory experience with colorful images of cities and landscapes from all over the world. Picturesque videos present various travel destinations, while built-in touch screens provide visual images that help future travelers make the right choice (Archilovers, 2015). Immersive VR gives travel marketers the opportunity to provide potential consumers with the most realistic experience of their destination (Barnes, 2016). AR applications enrich the tourist experience by bringing the history of destinations to life, while VR ones enhance the pre-trip tourist experience by giving a holistic view of the place itself (Marzouk et al., 2019). With the aim of delivering in-store VR technologies to customers, Thomas Cook travel company, together with Visyulaise (an extended reality studio), has produced a range of $360 \mathrm{VR}$ films that clients can use to explore potential destinations before booking. What is more, in 2016, Thomas Cook launched an online VR campaign on YouTube and Google Cardboard that allowed users to virtually move around a Thomas Cook's plane and also engage with short films about several locations. App Ascape, who has worked in partnership with Thomas Cook, also offers videos and tours of various places like San Francisco, Berlin, Cuba and many more (Consumer Technology Association, 2020). Leveraging innovative technology capabilities, Thomas Cook was the first travel company to deliver in-store VR to customers, and for this, it has been nominated for numerous innovation awards. These attempts were not for nothing since a high conversion rate for bookings made after viewing VR content was noted (Macaulay, 2019).

Using AR and VR applications as a marketing tool, a tour company can help convey experiences, increase customer awareness, and theoretically improve the destination image (Griffin et al., 2017). AR technology has created the basis for augmented reality marketing (ARM), an innovative and cutting-edge technology adopted by many commercial enterprises to strategize their marketing campaigns. Mobile AR applications can positively impact both marketing in general and a targeted travel campaign in particular. For example, the Zetta boutique hotel in San Francisco has set a VR installation in its lobby called Exit Reality. When guests put on an HMD, they are moved to various virtual worlds, from outer space to a sunken ghost ship. This use of VR not only entertains guests. Its location in the lobby creates an appealing feature that draws plenty of customers to the hotel. According to the Hotel Zetta administration, VR can be used to create some intrigue that stops people and therefore leads to an increase in clients (Huang, 2018). Hence, as a marketing tool, AR and VR must be given sufficient attention for development in terms of attaining the full potential to meet various tourist demands (Celtek, 2015).

As a technology-supported digital campaign, AR is popular with both corporate and consumer users. Generally, this advancement creates the foundation for more comprehensive, realistic, and complicated approaches to tourism and hospitality marketing. Consumers purchase travel services as a result of reliable and exciting information received through effective interaction. Therefore, the possibilities that AR can generate are quite convincing. This fact is inevitably linked with the abilities of AR to engage with consumers and enhance their satisfaction with the service offered. Hospitality and tourism marketers are increasingly taking the initiative to interact with technology, 
thereby providing channels for fruitful communication with consumers (Dadwal \& Hassan, 2016). AR systems can be effectively applied as a persuasive tool that delivers advantageous opportunities to market services (Celtek, 2015). It is a more engaging form of advertisement that helps people feel as if they are already at the point of destination. Tourism marketers should consider using AR to build relationships with potential visitors but not forget about traditional call-to-action marketing (Griffin et al., 2017).

VR and AR are excellent technologies for attracting tourists to countries with the aim of visiting individual tourist locations or even whole regions as they highlight top cultural sites and scenic areas. Many capital cities worldwide offer comprehensive virtual tours to famous neighborhoods and landmarks (Michel, 2020). For example, many of Paris' iconic cultural sites can now be viewed online (La Basilique du Sacré Cœur de Montmartre (n.d.), Opéra National de Paris (n.d.), Louvre (n.d.), etc.). Switzerland's immersive virtual experience allows travelers to view the peaks of St. Moritz, sit on the shores of Lake Lugano, or admire views of Zurich's historic cathedrals. All together, tourists can explore 22 lakes, five alpine passes, and 12 UNESCO sites without even leaving their home (Grand Tour of Switzerland, n.d.). Austria also demonstrates its most iconic sites with panoramic videos. Users can take a virtual boat tour along the Danube River or view the Ice Caves of Werfen and Mozart's residence (The Official Travel Portal, n.d.).

The United Arab Emirates (UAE) is a global leader in the use of VR and AR technologies for promoting regional tourism products. For example, the Dubai360 website, which has been launched back in 2014, offers virtual city tours, allowing users across the globe to visit Dubai utilizing the latest technologies. The website offers bird's-eye views of Dubai, including the iconic Palm Jumeirah and the World Islands, and takes a virtual tourist to the top of Burj Khalifa and inside the majestic Atlantis, The Palm. This virtual tour also showcases numerous other cultural destinations, such as the Etihad Museum, Dubai Museum, Al Fahidi Fort, and even several libraries and art galleries (Saundalkar, 2020). Given the strong and efficient entrepreneurial ecosystem that Dubai has to offer, its tourism sector continues to reap the benefits of powerful partnerships that propel the UAE toward becoming a global hub for innovations. The synergy between the private and public sectors to achieve common goals has become fertile ground for catalyzing innovations across the hospitality and tourism sector. Dubai has pioneered several innovative trends and technologies, including integrated mobile applications, audio tours, immersive gamification, digital reputation animation, and other means to enhance the travel product's attractiveness. Another striking example of the UAE's innovative course is the Visit Dubai mobile application designed for residents and tourists to explore Dubai's itineraries and events. Visit Dubai offers a wide range of features, such as a customizable My Trip tool that meets the current demand for personalized experiences. The Dubai Calendar website (and mobile application as well) is the official resource for all events and activities in the city, offering users a quick and easy way to discover and compare must-visit events without using numerous mobile platforms. Dubai Expert is another UAE's successful mobile application developed as an online training initiative for travel agents. It was launched in 2017 and now operates in 12 languages in 40 countries, focusing on targeting a wider travel audience internationally (Kazim, 2018). In 2018, two new virtual tours across Dubai were launched - Metro Moments and Al Fahidi Architecture Tour - available for free download in the Apple Store and Google Play. Supported by GPS technology, both tours use audio narrations to guide visitors through Dubai, automatically progressing from one point of interest to the next in real time, depending on a user's location. Metro Moments provides travelers with information on the various attractions that can be found along the Dubai Metro route between Dubai Airport Terminal 3 and the Dubai Mall. Al Fahidi Architecture Tour can be found on the Pocket Guide application, an electronic version of a human tour guide, assisting tourists with their travels in cities around the world. The tour focuses on presenting the rich history and heritage of Dubai's popular Al Fahidi District, part of the wider Dubai Historic District (Arabian Business, 2018). A useful application for UAE tourists is the AI Tour Guide chatbot, a 24/7 voice and text assistant. This interactive guide, which is accessible via WhatsApp, mobile application, Sharjah Commerce \& Tourism Development 
Authority's website, and Facebook messenger, shares accurate details about the UAE's top travel destinations, exciting events, world-class hotels, and leading restaurants (TravTalk, 2019).

The use of specially developed virtual worldwide tours will allow travel companies to qualitatively present the destination to a client and supplement a marketing proposal with bright multimedia content. In tourism marketing, video presentations remain an excellent tool for awakening the desire to visit a specific place (Minazzi, 2015). Facebook has introduced 360-degree photography and implemented video and live streaming as a first social media platform. Scientifically, it is defined as "immersive content". Immersive content with VR is seen as a future development direction, which has great potential in tourism (Julian, 2019). Travel companies in the UAE have realized the significance of digital marketing due to the positive effect of digital presence as an easy and cost-effective way to deliver information to potential customers via a tourism operator's official webpage. Communication through websites allows travel agents to reach out to clients and offer travel products, seminars, conferences, and various travel service options. Easy access to information is possible owing to the cutting-edge applications that assist marketing purposes on digital platforms (Gupta, 2019).

The urgency of creating a virtual tourist information system and developing its structure is necessary to comply with the innovative processes that involve modern VR and AR technologies. It allows operators to get new visual information and develop new travel products. The development of information technologies in the tourism industry can not only improve the functional efficiency of the industry but also introduce a new level of development through closer integration with other sectors of the economy (Vishnevskaya et al., 2017).

\section{CONCLUSIONS}

Rapid implementation of digital technologies in the field of tourism and hospitality increases the interest in the innovative technological solutions applied to solve the problems of tourism management, maximize profits, and ensure competitive advantages of a travel company from a long-term and strategic perspective. VR and AR technologies generate vast opportunities for travel operators in terms of planning, organization, management, and sale of travel products.

The article examined the experience of using immersive technologies in tour operators' prepurchase practice based on infrastructure capabilities of TUI Showroom interactive offices located in Russia and Ukraine. Studying the influence of an innovative commercial proposal on a client's decision to book a tour confirmed a high level of VR and AR technologies' efficiency. The conducted research showed that almost all the customers who have used TUI Showroom services booked a tour (95\%). What is more, the majority of respondents $(87 \%)$ claimed that the opportunity to immerse themselves in a virtual experience helped objectively evaluate a commercial offer and make a more rational and optimal decision. Provided digital tour information was highly appreciated by most clients (93\%). At the same time, $76 \%$ of respondents enjoyed up-to-the-minute innovations, excellent professionalism, and quality of service provided in the travel planning process, while $85 \%$ of customers indicated a desire to use TUI Showroom services again. Managers of Russian travel agencies showed a great interest in the innovations and confirmed the value and effectiveness of AR in tour-related consulting.

Investigation of the attitude of TUI Showroom's clients and managers of Russian travel agencies to the application of innovative technologies in travel consulting made it possible to outline the opportunities for practical use of mobile AR applications in the travel business. Furthermore, it enabled highlighting the key benefits from AR introduction in the modernization of management, production, and marketing functions of tour operators and travel agents. The use of AR and VR applications was proved to form economic, empirical, social, epistemic, educational, historical and cultural values for the tourism business. Immersive technologies are economically valuable for tour operators' activities because of their ability to maximize profits via attracting new target markets and increasing sales. Strengthening emotional attachment, trust, and customer loyalty forms the empirical value of mobile AR applications. In turn, the virtual environment of marketing opportunities capable of attracting new 
consumers creates the social value of AR in the tourism business. The epistemic value of AR arises from developing innovative means of communication with customers and capturing their attention by means of novel technologies and a desire to experience something new. The enhanced tourist's interest in the historical and cultural context of the tour, achieved by presenting the tour information from a new angle with improved reasoning and content, forms the historical and cultural value of AR. The educational value of AR arises from the innovative possibilities for providing high-quality tour information support, which is necessary for sales, personnel training, and fruitful collaboration with business partners.

The conducted research identified the advantages of introducing mobile AR applications into travel companies' pre-purchase practice. However, one should not forget that the possibilities of immersive technologies' application for solving tourism management problems are even more extensive. They can be used for planning or developing tours as well as for creating a tourism experience in a new innovative format. This provides a good starting point for further discussion and research.

Funding: This research received no specific grant from any funding agency in the public, commercial, or not-for-profit sectors.

Disclosure statement: The authors declare that there are no conflicts of interest related to this article.

Data availability statement: All data will be available on request.

Data deposition: Not applicable.

Geolocation information: Abu Dhabi, UAE 


\section{REFERENCES}

Ali, F. (2016). Hotel website quality, perceived flow, customer satisfaction and purchase intention. Journal of Hospitality and Tourism Technology, 7(2), 213-228. doi:10.1108/JHTT-02-2016-0010

Arabian Business. (2018). Dubai unveils new digital apps to boost tourism. https://www.arabianbusiness.com/ travel-hospitality/388869-dubai-unveils-new-digital-apps-to-boost-tourism

Archilovers. (2015). ADDIN. Travel Agency. https://www.archilovers.com/projects/165043/addin.html

Artefact. (n.d.). Official website. https://artefact.culture.ru

Barðeld, W., Bressler, D. M., \& Bodzin, A. M. (2013). A mixed methods assessment of students' ñow experiences during a mobile augmented reality science game. Journal of Computer Assisted Learning, 29(6), 505-517. doi:10.1111/jcal.12008

Barnes, S. (2016). Understanding virtual reality in marketing: nature, implications and potential. https://papers. ssrn.com/sol3/papers.cfm?abstract_id=2909100

Best Western Hotels \& Resorts. (2018). Fast company names best western ${ }^{\circledR}$ hotels \& resorts one of top 10 most innovative companies in AR/VR. www.bestwestern.com/en_US/about/press-media/2018-press-release/ bw-named-one-of-top-10-most-innovative-companies.html

Celtek, E. (2015). Smart technologies: Augmented reality applications in tourism marketing. In K. Wolfe, C. Henning, \& A. DeMarco (Eds.), Emerging Innovative Marketing Strategies in the Tourism Industry (pp. 116-132). IGI Global. doi:10.4018/978-1-4666-8699-1.ch007

Consumer Technology Association. (2020). Redefining Travel and Tourism with AR and VR. https://www.ces. tech/Articles/2020/Redefining-Travel-and-Tourism-with-AR-and-VR.aspx.

Coral Travel. (n.d.). Official website. https://www.coraltravel.ua/coral-mobile-app

Dadwal, S. S., \& Hassan, A. (2016). The augmented reality marketing: A merger of marketing and technology in tourism. In Mobile Computing and Wireless Networks: Concepts, Methodologies, Tools, and Applications (pp. 63-80). IGI Global. doi:10.4018/978-1-4666-8751-6.ch004

Digital Binocular Station. (n.d.). Official website. http://digitalbinocularstation.com/the_dbs

Dirin, A., \& Laine, T. H. (2018). User experience in mobile augmented reality: Emotions, challenges, opportunities and best practices. Computers, 7(2), 33. doi:10.3390/computers7020033

Grand Tour of Switzerland. (n.d.). Official website. https://grandtour.myswitzerland.com/en/

Griffin, T., Giberson, J., Lee, S. H., Guttentag, D., Kandaurova, M., Sergueeva, K., \& Dimanche, F. (2017). Virtual Reality and Implications for Destination Marketing. In Travel and Tourism Research Association: Advancing Tourism Research Globally. https://scholarworks.umass.edu/ttra/2017/academic_papers_oral/29

Gupta, G. (2019). Inclusive use of digital marketing in tourism industry. In S. C. Satapathy, V. Bhateja, R. Somanah, X.-S. Yang, \& R. Senkerik (Eds.), Information Systems Design and Intelligent Applications (pp. 411-419). Springer. doi:10.1007/978-981-13-3329-3_38

Guttentag, D. A. (2010). Virtual reality: Applications and implications for tourism. Tourism Management, 31(5), 637-651. doi:10.1016/j.tourman.2009.07.003

Han, D. I. D., Weber, J., Bastiaansen, M., Mitas, O., \& Lub, X. (2019). Virtual and augmented reality technologies to enhance the visitor experience in cultural tourism. In M. C. tom Dieck \& T. Jung (Eds.), Augmented reality and virtual reality (pp. 113-128). Springer. doi:10.1007/978-3-030-06246-0_9

Huang, N. (2018). Innovative ways travel brands are using virtual reality. https://www.pegs.com/blog/innovativeways-travel-brands-are-using-virtual-reality/

Julian, J. (2019). Socialbakers. Načteno z Top 5 Social Media Marketing Formats for 2017. https://www. socialbakers.com/blog/2659-top-5-social-media-marketing-tips-for-2017 
Kazim, I. (2018). How technology is driving tourism in Dubai. https://www.khaleejtimes.com/editorials-columns/ how-technology-is-driving-tourism-in-dubai

Kounavis, C. D., Kasimati, A. E., \& Zamani, E. D. (2012). Enhancing the tourism experience through mobile augmented reality: Challenges and prospects. International Journal of Engineering Business Management, 4, 1-10. doi:10.5772/51644

La Basilique du Sacré Cœur de Montmartre. (n.d.). Official website. http://www.sacre-coeur-montmartre.com/ english/visit-and-audio-guide/article/panoramic-virtual-tour

Lemon, K. N., \& Verhoef, P. C. (2016). Understanding customer experience throughout the customer journey. Journal of Marketing, 80(6), 69-96. doi:10.1509/jm.15.0420

Locals.Maps.me. (n.d.). Official website. https://locals.maps.me/

Loureiro, S. M. C., Guerreiro, J., \& Ali, F. (2020). 20 years of research on virtual reality and augmented reality in tourism context: A text-mining approach. Tourism Management, 77, 104028. doi:10.1016/j.tourman.2019.104028

Louvre. (n.d.). Official website. https://www.louvre.fr/en/visites-en-ligne

Macaulay, T. (2019). How UK companies are using virtual reality and augmented reality. https://www. computerworld.com/article/3428117/how-uk-companies-are-using-virtual-reality-and-augmented-reality.html

Marzouk, A., Maher, A., \& Mahrous, T. (2019). The Influence of Augmented Reality and Virtual Reality Combinations on Tourist Experience. Journal of the Faculty of Tourism and Hotels-University of Sadat City, 3(2), 1-19. doi:10.21608/mfth.2019.71071

Michel, O. (2020). The Best Virtual Travel Experiences to Enjoy Now. https://www.boatinternational.com/ destinations/virtual-travel-tours-trips-vr-experiences--43207

Minazzi, R. (2015). Social Marketing in Tourism and Hospitality. Springer International Publishing. doi:10.1007/978-3-319-05182-6

Nayyar, A., Mahapatra, B., Le, D., \& Suseendran, G. (2018). Virtual Reality (VR) \& Augmented Reality (AR) technologies for tourism and hospitality industry. International Journal of Engineering \& Technology, 7(2.21), 156-160.

Nóbrega, R., Jacob, J., Coelho, A., Weber, J., Ribeiro, J., \& Ferreira, S. (2017). Mobile location-based augmented reality applications for urban tourism storytelling. In $201724^{\circ}$ Encontro Português de Computação Gráfica e Interação (EPCGI) (pp. 1-8). IEEE. doi:10.1109/EPCGI.2017.8124314

Opéra National de Paris. (n.d.). Official website. https://artsandculture.google.com/partner/op\%C3\%A9ranational-de-paris?hl=en

Özkul, E., \& Kumlu, S. T. (2019). Augmented reality applications in tourism. International Journal of Contemporary Tourism Research, 2, 107-122. doi:10.30625/ijctr.625192

Pierdicca, R., Paolanti, M., \& Frontoni, E. (2019). eTourism: ICT and its role for tourism management. Journal of Hospitality and Tourism Technology, 10(1), 90-106. doi:10.1108/JHTT-07-2017-0043

Qiao, X., Ren, P., Nan, G., Liu, L., Dustdar, S., \& Chen, J. (2019). Mobile web augmented reality in 5G and beyond: Challenges, opportunities, and future directions. China Communications, 16(9), 141-154. doi:10.23919/ JCC.2019.09.010

Rezaei, S., Ali, F., Amin, M., \& Jayashree, S. (2016). Online impulse buying of tourism products: The role of web site personality, utilitarian and hedonic web browsing. Journal of Hospitality and Tourism Technology, 7(1), 60-83. doi:10.1108/JHTT-03-2015-0018

Rivera, M., Gregory, A., \& Cobos, L. (2015). Mobile application for the timeshare industry. Journal of Hospitality and Tourism Technology, 6(3), 242-257. doi:10.1108/JHTT-01-2015-0002

Saundalkar, A. (2020). Take a virtual city tour of Dubai with Dubai360. https://whatson.ae/2020/05/take-avirtual-city-tour-of-dubai-with-dubai360/ 
Shang, L. W., Siang, T. G., Zakaria, M. H. B., \& Emran, M. H. (2017). Mobile augmented reality applications for heritage preservation in UNESCO world heritage sites through adopting the UTAUT model. In. AIP Conference Proceedings: Vol. 1830. No. 1 (p. 030003). AIP Publishing LLC. doi:10.1063/1.4980928

Tan, G. W. H., Lee, V. H., Lin, B., \& Ooi, K. B. (2017). Mobile applications in tourism: The future of the tourism industry? Industrial Management \& Data Systems, 117(3), 560-581. doi:10.1108/IMDS-12-2015-0490

Taylor, M. (2018). Marriott Launches Augmented Reality App. Travel Pulse. https://www.travelpulse.com/news/ hotels-and-resorts/marriott-launches-augmented-reality-app.html

The Official Travel Portal. (n.d.). 11 Places in Austria You Can Visit Right Now, Virtually. https://www.austria. info/en/virtual-austria/places

tom Dieck, M. C., \& Jung, T. (2018). A theoretical model of mobile augmented reality acceptance in urban heritage tourism. Current Issues in Tourism, 21(2), 154-174. doi:10.1080/13683500.2015.1070801

TravTalk. (2019). Sharjah Tourism introduces 'AI Tour Guide Chatbot'. https://travtalkmiddleeast.com/sharjahtourism-introduces-ai-tour-guide-chatbot/

Tui Group. (n.d.). Official website. https://www.tuigroup.com

Tussyadiah, I. P., Wang, D., Jung, T. H., \& tom Dieck, M. C. (2018). Virtual reality, presence, and attitude change: Empirical evidence from tourism. Tourism Management, 66, 140-154. doi:10.1016/j.tourman.2017.12.003

Van Krevelen, D. W. F., \& Poelman, R. (2010). A survey of augmented reality technologies, applications and limitations. The International Journal of Virtual Reality: a Multimedia Publication for Professionals, 9(2), 1-20. doi:10.20870/IJVR.2010.9.2.2767

Vishnevskaya, E. V., Klimova, T. B., Slinkova, O. K., \& Glumova, Y. G. (2017). The influence of virtual information spaces on tourism development. Espacios, 38(49), 22-29.

Wikitude. (n.d.). Official website. https://www.wikitude.com/

Yin, C. Z. Y., Jung, T., \& Lee, M. Y. (2021). Mobile augmented reality heritage applications: Meeting the needs of heritage tourists. Sustainability, 13(5), 2523. doi:10.3390/su13052523

Yung, R., \& Khoo-Lattimore, C. (2019). New realities: A systematic literature review on virtual reality and augmented reality in tourism research. Current Issues in Tourism, 22(17), 2056-2081. doi:10.1080/13683500 .2017 .1417359

Ahmad Ghandour's research interests include the use of immersive technologies as a marketing tool in tourism management.

Aliya Kintonova's research interests include the use of augmented reality applications in tourism.

Natalya Demidchik's research interests include use of immersive technologies in tourism.

Elena Sverdlikova's research interests include mobile augmented reality applications. 